\title{
Teaching Argument Diagrams to a Student Who Is Blind
}

\author{
Marc Champagne $^{(\mathbb{\infty})}$ (1) \\ Trent University, Peterborough, ON K9L 0G2, Canada \\ thinkingmarcchampagne@gmail.com
}

\begin{abstract}
This paper describes how bodily positions and gestures were used to teach argument diagramming to a student who cannot see. After listening to short argumentative passages with a screen reader, the student had to state the conclusion while touching his belly button. When stating a premise, he had to touch one of his shoulders. Premises lending independent support to a conclusion were thus diagrammed by a V-shaped gesture, each shoulder proposition going straight to the conclusion. Premises lending dependent support were diagrammed by a T-shaped gesture, the shoulder premises meeting at the collar bone before moving down to the belly button. Arguments involving two pairs of entailments were diagrammed by an I-shaped gesture, going from the collar bone to a mid-way conclusion above the abdomen before travelling to the final conclusion at the belly button. The student's strong performance suggests that placing propositions at different locations on the body and uniting them with gestures can help one discern correct argumentative structures.
\end{abstract}

Keywords: Arguments $\cdot$ Body $\cdot$ Gestures

Last year, I did something I had never done before: I taught argument diagramming to a student who cannot see. Shortly before the start of classes, I was informed by my university's Accessibility Services that one of my students was blind and would therefore need accommodations. This posed a problem, since I usually spend the first month of my Critical Thinking course teaching students how to convert argumentative texts into diagrams with numbers and arrows. It was made clear to me that, given the costs and delays involved, Braille was not an option (even with unlimited resources, Braille struck me as an inferior option). A puzzle-like device has been built to help blind students figure out categorical syllogisms [1], but syllogisms are only one type of argument, while I was aiming for greater generality. I could have assigned different course content. However, I had just published an article arguing that non-visual logics are possible [2]. My student's needs let me put this academic background to good use.

Diagrams are signs that mimic only relations, not relata [3]. Consider the argument diagrams taught in Critical Thinking courses. Typically, individual propositions are represented by numbers. Although this numerical assignment is arbitrary, the skeletal structure that emerges when one relates the numbers is not, since that structure is answerable to the logical relations holding among the various propositions. I was already committed in print to the idea that diagrams can express such relations non-visually, so I liked the idea of now putting that commitment to the test. 
Research has shown that, "[i]f the environment in which learning occurs is not supportive to students with visual impairments, their learning will automatically be interrupted" ([4], pp 22-23). I therefore met with my student beforehand, at the start of the term. When he came to my office, I could sense that he was nervous. I therefore broke the ice: "Listen, I'm going to be frank. I have never taught argument diagrams with any channel other than vision. I have some promising ideas about how we might do this. But, I want to be clear from the get-go that this will be a first, for both of us." This transparency put him at ease. The epistemological fallibilist in me then stepped in: "Let's start from the assumption that we are going to mess up. If we indeed mess up, then I will give you a month-long extension, so that you can complete a different chapter from our textbook. If, however, things work and you end up acquiring the skill in question, there will be no need for an extension. Agreed?" He agreed.

Our first session was devoted to introducing the method. The goal was to translate a string of symbols, namely a textual passage, into a diagram that exhibits the argumentative structure at play in that passage. My student showed me how he uses a computer program to hear (in a monotone robotic voice) what is written. Importantly, he has to remember all that he hears. Since there are limits to what one can recall, I decided to make adjustments. First, I made sure that the arguments would be at most three propositions long (we were going to spend a mere four weeks on this, so we had to pick battles big enough to matter but small enough to win). Second, I typed all the passages in a simple Text document, since I discovered that extra formatting merely hindered his computer reader. Third, I made sure to skip a line after each sentence. The computer program did not make any noticeable pause when it encountered a period, so I wanted to give my student a chance to really bite down on these grammatical units. Fourth, I typed out the exercise numbers with regular language, since the computer program reads numbers 0 to 9 quite well but starts saying things like "One Six" when it encounters larger numbers like "16." Finally, I lifted all time constraints and allowed my student to listen to auditory contents as often as he wished.

The opening drill consisted in listening to a variety of arguments and picking out the main conclusion. What is the point being made? My student had to state this conclusion out loud. I gave him immediate feedback after each answer. To supply him with exercises, I usually brought a USB key with a Text file that he copied onto his laptop. However, for this warm-up exercise, I read him the arguments from a book, repeating them in a clear voice whenever he wished.

The second task was similar to the first, only this time my student had to pick out the reasons given to support the conclusion. I noticed that he had a tendency to shorten the sentences by rewording them. I warned against doing this, since important parts connecting the premises risk being discarded.

In the next task, we started incorporating the body. The goal was to exploit my student's prior familiarity with his own lived body in order to structure the layout of arguments. When stating a conclusion out loud, he had to touch his belly button. When stating a premise, he had to touch one of his shoulders. Since I could see him making these gestures, he no longer had to preface his answers with verbal locutions like "The conclusion is..." and "The first premise is..." Because we were working with a maximum of three propositions, there was always enough space on his torso to locate the relevant constituents of an argument. 
At this early stage, I included only two types of arguments, namely those where the premises lend dependent support and those where they lend independent support. Once my student has pinned the conclusion to his belly button, he would determine the type of support by going from one shoulder to the belly and asking whether that relation made any sense. Independent relations of support were thus signified by a V-shaped gesture where each shoulder proposition went straight to the conclusion. An example of an independent argument would be "Sushi is made from seaweed. Sushi is made from rice. Therefore, sushi contains plant matter." Dependent relations of support were signified by a T-shaped gesture that first connected the premises at the collar bone before moving straight down to the belly button. An example of a dependent argument would be "Either the baby in my belly is kicking or I have gas. I do not have gas. Therefore, the baby is kicking." As my student announced the propositions and performed the gestures, he looked like a Christian making the sign of the cross.

For every argument, I required my student to move in two directions before settling on his answer. When working downward from the shoulders to the belly button, he had to use connecting words like "and" and "Therefore," timing those verbal cues with his gestures. When moving upward from his belly button to his shoulders, he had to use transition words like "Why? Because..." If there was an error in his preliminary diagram, it tended to get exposed when it was tested in both directions.

After three weeks of practice, I felt that my student was ready for his first quiz. This quiz was comprised of 10 questions, each worth $1 \%$. He had his headphones on, so I was unable to hear how many times he re-listened to the texts on his computer. I think this privacy was a good thing, since it left him free to listen to the arguments as many times as he needed, without worrying about what I might think. While he deliberated, I worked silently on something else (I told him as much). My student tended to do his trial gestures silently. However, I think that talking out loud would have been better, pedagogically speaking. In any event, when he was done toying with an argument, he notified me that he was ready to give his answer. I would then look and listen as he diagrammed the argument. I graded his results silently on a notepad, scoring his answers in an all or nothing manner, giving 1 point for a perfect diagram and 0 for anything else. I was able to divulge his quiz result immediately after he was done.

My student was clearly intent on doing well, so he was putting a lot of pressure on himself. In previous sessions, I noticed that he would occasionally rush to a verdict. Diagrammatic reasoning is at its most fertile when it includes an element of play, so I encouraged my student to toy creatively with the different logical-cum-gestural relations, feeling out which fits best.

The weeks of in-office and at-home practice proved sufficient, since my student earned 10 out of 10 for his quiz. We kept practicing for a more challenging test that would be worth $25 \%$. This test added a new diagram to the mix, namely chain arguments. In this structure, a premise (starting at the collar bone) leads to a mid-way conclusion (located above the abdomen) which in turn serves as a premise for a final conclusion (at the belly button). If dependent support is T-shaped and independent support is V-shaped, then this iterated relation of entailment yields a bodily diagram that is I-shaped. An example of a chain argument would be "Sarah must go visit her parents for the holidays. As a result, she will need to take the train. Therefore, she will need money." What I learned was that, on its own, this diagrammatic structure was 
easy to grasp, no doubt because it reduces the threefold linkage to two pairs. That said, when chain arguments were randomly mixed with dependent and independent arguments, they became harder to spot. My student scored 20 out of 25 for this test.

All told, we worked on bodily diagramming for a month before moving on to the next course content. One promising possibility we had no time of exploring is that of recycling a conclusion into a premise, by sliding it from the belly button to a shoulder. I suspect that, once mastered, this could allow one to handle lengthier arguments.

In any event, the foregoing has been predicated on a realistic, not an idealized, conception of how inquiry proceeds. Innovations emerge from the vicissitudes of practical engagements (that are often best expressed in a narrative format). While the positive learning/teaching experience I have recounted was insufficiently controlled to justify full-on theses about diagrammatic reasoning and argumentative cognition, my student's strong performance suggests that placing propositions at different locations on the body and uniting them with gestures can help one discern correct argumentative structures.

Although the diagramming method that I have described was designed to meet special learning needs, I see no reason why it could not be used in regular class contexts. The next step, then, would be to teach this method to more students (as a main skill or side drill), make adjustments where necessary, and report back the findings. Teachers and students are well placed to judge whether a given exercise works, so ideally their first-hand reports should be incorporated into experimental designs [5].

Given that there are always students who recoil from mainstream notations, it might be worthwhile to have an alternative method on stand-by that appeals to a sense modality other than sight. There are many ways to learn [6] and many ways to make an argument [7], so hopefully this bodily diagramming can add a useful arrow to the teacher's quiver.

\section{References}

1. Goldstein, L.: Adding a dimension to logic diagramming. In: Blackburn, P., van Ditmarsch, H., Manzano, M., Soler-Toscano, F. (eds.) TICTTL 2011. LNCS (LNAI), vol. 6680, pp. 101108. Springer, Heidelberg (2011). https://doi.org/10.1007/978-3-642-21350-2_13

2. Champagne, M.: Sound reasoning (literally): Prospects and challenges of current acoustic logics. Logica Universalis 9, 331-343 (2015). https://doi.org/10.1007/s11787-015-0127-7

3. Peirce, C.S.: Collected Papers. Harvard University Press, Cambridge (1931-1958)

4. Mwakyeja, B.M.: Teaching students with visual impairments in inclusive classrooms. Master's thesis, Faculty of Educational Sciences. University of Oslo, Oslo (2013). https:// www.duo.uio.no/bitstream/handle/10852/36642/MasterxsxThesis.pdf?sequence=1

5. Gallagher, S., Sørensen, J.B.: Experimenting with phenomenology. Conscious. Cogn. 15, 119-134 (2006). https://doi.org/10.1016/j.concog.2005.03.002

6. Gardner, H.: Frames of Mind: The Theory of Multiple Intelligences. Basic, New York (2011)

7. Groarke, L.: Going multimodal: What is a mode of arguing and why does it matter? Argumentation 29, 133-155 (2015). https://doi.org/10.1007/s10503-014-9336-0 